5 Marx GF. Cardiotoxicity of local anesthetics - The plot thickens (Editorial). Anesthesiology 1984; 60: 3-5.

6 Bedell SE, Delbanco TL, Cook EF, Epstein FH. Survival after cardiopulmonary resuscitation in the hospital. N Engl J Med 1983; 309: 569-76.

7 Rosenberg PH, Kalso EA, Tuominen MK, Linden $H B$. Acute bupivacaine toxicity as a result of venous leakage under the tourniquet cuff during a Bier block. Anesthesiology 1983; 58: 95-8.

8 Marx GF. Maternal complications of regional analgesia. Regional Anesthesia 1981; 6: 104-7.

9 Datta S, Corke BC, Alper MH, Brown WU, Ostheimer $G W$, Weiss $J B$. Epidural anesthesia for Cesarean section: a comparison of bupivacaine, chloroprocaine and etidocaine. Anesthesiology 1980; 52: 48-51.

10 James FM III, Dewan DM, Wheeler AS, Grant WM, Rhyne L, Westmoreland RT. Chloroprocaine vs. bupivacaine for lumbar epidural analgesia for elective Cesarean section. Anesthesiology 1980; 52: 488-91.

11 Cohen SE, Wyner J. Post-cesarean section narcotic requirements following epidural anesthesia with bupivacaine and chloroprocaine. Regional Anesthesia $1980 ; 515-6$.

12 Albright $G A$. Cardiac arrest following regional anesthesia (Editorial). Anesthesiology 1979; 51: $285-7$.

13 Kotelko DM, Shnider SM, Brizgys RV et al. Bupivacaine induced arrhythmias in sheep. Anesthesiology 1984; 60: 10-8.

14 Thigpen JW, Kotelko DM, Shnider SM et al. Bupivacaine cardiotoxicity in hypoxic-acidotic sheep. Anesthesiology 1983; 59: A204.

15 Clarkson CW, Hondeghem L. Matsubara T, Levinson $G$. Possible mechanism of bupivacaine toxicity: fast inactivation block with slow diastolic recovery (Abstract)., Anesth Analg 1984; 63: 199.

16 Wojtczak JA, Griffin RM, Pratilas V, Kaplan JA. Is it possible to resuscitate a bupivacaine-intoxicated heart? Anesthesiology 1984; 61: A207.

17 Kasten GW, Martin ST. Successful resuscitation after massive intravenous bupivacaine overdose in hypoxic dog. Anesthesiology 1984; 61: A206.

\section{The rational use of bupivacaine in obstetric epidural anaesthesia}

W.D.R. Writer MB CH B FRCPC, Departments of Anaesthesia and Obstetrics \& Gynaecology, Grace Maternity Hospital, Dalhousie University, Halifax, Nova Scotia, Canada, B3H 1 V9.

In August, 1983, Canadian anaesthetists were advised by the Drugs Directorate of the Health Protection Branch of the Department of National Health and Welfare, Ottawa, in conjunction with the drug company, Winthrop Laboratories, that bupivacaine 0.75 per cent was no longer recommended for use in obstetric analgesia and anaesthesia.* This advisory resulted from American reports of cardiac arrest in patients receiving this concentration of the drug. $t \neq$ Since then, two Canadian publications have commented on the advice concerning bupivacaine, ${ }^{2} \S$ and recommended techniques for the safe use of the drug. However, despite reports about its possible cardiotoxicity, bupivacaine remains the preferred local anaesthetic agent in obstetric anaesthesia and has three major uses.

\section{Epidural analgesia in labour}

Continuous epidural analgesia (intermittent injection)

Since epidural drug dose requirements are reduced

* Blair $I$. New recommendations about bupivacaine (Letter). Winthrop Laboratories. 29 August, 1983. $\dagger$ Albright GA. Clinical aspects of bupivacaine toxicity. Report to Anesthetic and Life Support Drugs Advisory Committee, United States Department of Health and Human Services. October 4, 1983.

†Food and Drug Administration (FDA) Drug Bulletin. Department of Health and Human Services. 1983; 13: 23.

$\S$ McMorland GH, Biehl DR, Palahniuk RJ. Report of the Canadian Anaesthetists' Society Ad Hoc Committee on cardiotoxicity of bupivacaine. May, 1984. 
in pregnancy, lower anaesthetic concentrations allow use of the smallest effective dose; additionally, minimal motor block is produced, an important obstetric consideration. Bupivacaine's potency and long duration of action prolong the interval between top-ups; the drug's latency of onset has little significance in clinical practice. Thus, 0.25 or 0.125 per cent solution works well in a dose of $25-30 \mathrm{mg}$ (i.e., $10-12 \mathrm{ml}$ of 0.25 per cent). ${ }^{3} \mathrm{An}$ increase in foetal heart rate decelerations has been reported, but the aetiology and significance of this remain uncertain. ${ }^{4}$

\section{Continuous infusion analgesia}

Infusion techniques offer smoother control of labour pain, with less need for incremental doses. ${ }^{5}$ However, since infusions result in a larger total dose of local anaesthetic, ${ }^{6}$ accidental intravascular or subarachnoid administration must be carefully excluded. More dilute concentrations seem preferable, but paradoxically appear to cause more motor block than the administration of solutions of higher concentration. ${ }^{7}$ Bupivacaine $0.25-0.3$ per cent provides effective pain relief with an hourly dose of $15-18 \mathrm{mg} .{ }^{5}$ The incidence of forceps delivery is increased in women receiving continuous infusion analgesia with bupivacaine in comparison to those receiving chloroprocaine or lidocaine. ${ }^{8}$ But use of the latter two shorter-acting drugs ${ }^{8}$ can also lead to tachyphylaxis. In the author's experience bupivacaine tachyphylaxis, although reported, ${ }^{8}$ is rare.

\section{Anaesthesia for Caesarean section}

The requirement for an extensive block, from T5-S5, increases the potential for major problems. The deaths in the United States of America apparently resulted from inadvertent intravascular injection of bupivacaine. ${ }^{1} \uparrow$ The danger with 0.75 per cent bupivacaine lay in the ability to administer too much too quickly, ${ }^{9}$ and therefore this concentration is no longer recommended for obstetric use.*

Bupivacaine 0.5 per cent can provide excellent Caesarean section analgesia in most parturients. The use of an initial dose with the patient seated improves sacral block. Essential safety measures include slow injection of the drug with increments not exceeding $5 \mathrm{ml}$ and careful and repeated aspiration. Accidental intravascular or subarachnoid placement of the cannula must be carefully excluded. Three ml local anaesthetic plus $15 \mu \mathrm{g}$ epinephrine $(1: 200,000)^{10}$ and a simple "manometer" test " have a great degree of reliability.

Like all potentially hazardous drugs, bupivacaine demands respect. Maximum recommended dosage for Caesarean section is $2-2.5 \mathrm{mg} \cdot \mathrm{kg}^{-1}$ (150$200 \mathrm{mg})^{12}$ and with continuous use in labour, $2 \mathrm{mg} \cdot \mathrm{kg}^{-1}$ should not be exceeded in a four hour period. ${ }^{13}$ These dose limits also apply when existing epidural analgesia needs augmentation for Caesarean section.

Bupivacaine remains popular for Caesarean section anaesthesia. Its prolonged duration gives excellent sensory analgesia with less motor block than lidocaine or chloroprocaine. When time is of the essence, as in foetal distress, chloroprocaine (or possibly lidocaine) may be preferred; otherwise bupivacaine retains a broad spectrum of indications in obstetric anaesthesia.

\section{References}

1 Albright $G A$. Cardiac arrest following regional anaesthesia with etidocaine or bupivacaine. Anesthesiology 1979; 51 : 285-7.

2 Writer WDR, Davies JM, Strunin L. Trial by media: the bupivacaine story. Can Anesth Soc J 1984; 31: 1-4.

3 Bleyaert A, Soetens $M$. Vaes $L$ et al. Bupivacaine, 0.125 per cent, in obstetric epidural analgesia: experience in three thousand cases. Anesthesiology 1979 ; 51: 435-8.

4 Abboud TK, Khoo SS, Miller F, Doan T, Hendriksen $E H$. Maternal, fetal, and neonatal responses after epidural anesthesia with bupivacaine, 2-chloroprocaine or lidocaine. Anesth Analg 1983; 61: 638-44.

5 Taylor HJC. Clinical experience with continuous epidural infusion of bupivacaine at $6 \mathrm{ml}$ per hour in obstetrics. Can Anaesth Soc J 1983; 30: 277-85.

6 Nadeau $S$, Elliott $R D$. Continuous bupivacaine infusion during labour: effects on analgesia and delivery Can Anaesth Soc J 1984; 31: S70-1.

7 Kenepp NB. Cheek TG, Gutsche BB. Bupivacaine: continuous infusion epidural analgesia for labour. Anesthesiology 1983; 59: A407.

8 Abboud TK, Afrasiabi A, Sarkis F et al. Matemal, fetal and neonatal effects of continuous epidural infusion analgesia. Anesthesiology 1983; 59: A408.

9 Scott, $D B$. Toxicity caused by local anaesthetic agents. Br J Anaesth 1984; 56: 435-6.

10 Moore DC, Batra MS. The components of an effective test dose prior to epidural block. Anesthesiology 1981; 55: 693-6. 
11 Shah $J L$. A test to show correct placement of epidural catheter. Anaesthesia 1982; 37: 426-7.

12 Hodgkinson R. Potential interactions between cimetidine and amide local anesthetics in obstetrics ( $R e$ ply). Anesthesiology 1984; 60: 508-9.

13 Thorburn J, Moir DD. Bupivacaine toxicity in association with extradural analgesia for Cacsarean section. Br J Anaesth 1984; 56: 551-2.

\section{Medical indications for regional anaesthesia}

James G. Glassford MD FRCPC, Department of Anaesthesia, Foothills Hospital at the University of Calgary, Calgary, Alberta, Canada, T2N 2T9.

Although many specialists in internal medicine think that they should help influence the choice of anaesthetic technique, the decision between regional and general anaesthesia in any given medical condition and surgical procedure is best left to the attending anaesthetist. Many factors influence the choice of anaesthesia.* These include patient attitude, size and metabolic-physiologic status, anaesthetist skills, accessory personnel and facilities, operative site and duration of operation, and therapeutic and diagnostic considerations.

Recent additions and advances in anaesthetic drugs and techniques for general anaesthesia, the increasing number of otherwise well-trained anaesthetists who have limited experience with regional techniques, and the inherent suspicion and fear of surgeons and their patients toward blocks have conspired to limit the use of regional anaesthesia. ${ }^{1}$ As a result, appropriate and optimal use of local anaesthetics is often neglected, resulting in even less inclination to consider regional techniques. The economic pressure to use operating theatre time for

*Carle HL. Regional Anaesthesia. Canadian Anacsthetists' Society Western Divisions Meeting Programme Papers, Edmonton, 1984. the maximum number of cases also mitigates against regional anaesthesia, which, especially in less experienced hands, often takes longer than general anaesthesia. It is interesting to note that among anaesthetists, 68 per cent of 3,498 respondents in a survey preferred regional anaesthesia for themselves. ${ }^{2}$ Reasons cited by them for choosing regional anaesthesia included ease of administration, lower incidence of major intraoperative or postoperative complications, avoidance of the toxic effects of some general anaesthetic agents, provision of excellent operating conditions, pleasant recovery, and less difficulty in the recovery room.

Regional anaesthesia may be preferred in outpatients, emergency surgery without extensive haemorrhage, patients with a full stomach, surgery in the prone position, geriatric patients, hot and dry climates or high altitude, and surgery where patient co-operation is required. ${ }^{3}$ Local techniques may also be selected in patients with certain disease states: diabetes, hypertension, coronary artery disease, congestive heart failure, cerebrovascular accidents, respiratory disease, and urinary tract disease. In contrast, preference may be given to general anaesthesia in young, unco-operative or uncomprehending patients, hysterical patients, patients with a history of malingering, certain nervous system diseases, anaemias, coagulopathies, skin infections, and septicaemia.

There are few controlled scientific studies which attempt to determine the relative advantages of either form of anaesthesia. Recent data have demonstrated the merits of regional anaesthesia with respect to haemodynamic considerations, metabolic effects, postoperative patient care, and relative morbidity and mortality. ${ }^{4}$ Cardiovascular depression is less and metabolic stress responses are better obtunded. ${ }^{5}$ Postoperatively there is improved pulmonary function, better pain control, and earlier ambulation and discharge. ${ }^{6}$ Mortality rates have been shown to be slightly lower in regional anaesthesia. ${ }^{7,8}$

Nevertheless, large scale epidemiologic studies need to be done to further elucidate the relative advantages of regional and general anaesthetic techniques.

\footnotetext{
References

1 Moore DC. Regional Block. 4th ed, Springfield, Illinois, Charles C. Thomas, 1978.
} 